\title{
Analyses on Dynamic Solid Flow in Blast Furnace Lower Part by Deadman Shape and Raceway Depth Measurement
}

\author{
Yoshiyuki MATSUI, Mutsumi TANAKA, ${ }^{1)}$ Muneyoshi SAWAYAMA, Shinji KITANO"1), Takashi IMAI' ${ }^{21}$ and \\ Akiyoshi GOTO2) \\ R \& D Lab., Kobe Steel, Ltd., 2222-1, Ikeda, Onoe-cho, Kakogawa, Hyogo 675-0023 Japan. \\ 1) Kakogawa Works, Kobe Steel, Ltd., 1, Kanazawa-cho, Kakogawa, Hyogo 675-0137 Japan. \\ 2) Electrical, Instrument and Computer Division, Shinko EN \& M Co., Ltd., 1, Kanazawa-cho, Kakogawa, Hyogo 675-0137 Japan.
}

(Received on February 28, 2005; accepted on July 4, 2005)

\begin{abstract}
As one of the factors of frequent troubles that occur in the transition period from all-coke operation to PC injection operation in blast furnace as well as increased troubles in recent years, increased size of the blast furnace and high-productivity operation are pointed out. Consequently, great importance is attached to burden distribution control and burden descent condition, or control of melting zone, deadman shape, solid flow at the lower part of furnace and others. In the present study, the reduced stockline surface profile was measured by the reflection intensity of microwave struck from the furnace top after blow-off with stockline reduced, and investigation was made on the countermeasures for changes in the raceway depth and furnace body profile during operation. As a result, it has been clarified that flow-down of coke into the lower part of blast furnace and inflow into the raceway are greatly subject to the existence of deadman which is the packed structure of the lower part of furnace, and further, they are closely related to dynamic behavior of the raceway and affect changes of the furnace body profile.
\end{abstract}

KEY WORDS: blast furnace; deadman; raceway; micro wave; coal injection; coke; unsteady phenomena.

\section{Introduction}

While at home, the growth of crude steel production has been saturated and production integration to large-size blast furnaces takes place to secure primary iron sources, stability in high productivity operation becomes the center of attention of the people concerned. With respect to the role of deadman of the large-size blast furnace, there are people who do not think it as a white elephant and value its calorie holding function and do not regard deadman inactive but active, and heated arguments are made on the methodology of maintaining the activity, and as a result, the importance of coke quality has been recognized anew. On the other hand, there are opinions to place attention to adverse effects of increasing the hearth diameter and to have the minimum hearth diameter in order to secure the tuyere diameter and fuel combustion capability because fine coke discharge from deadman depends on the molten iron and slag passing capability of itself. ${ }^{1)}$

In addition, operation under pulverized coal (hereinafter called PC) injection tends to cause frequent operation troubles and a greater number of troubles are generated in the transition time from all coke to PC injection. As one of the factors of the recent increase of troubles, so increased size of the blast furnace and high productivity operation are pointed out. Consequently, control of burden distribution and burden descent condition in the increased size of blast furnace and high productivity operation, as well as control of melting zone, deadman profile, solid flow at the lower part of furnace, etc. have been valued highly.

In the past, with respect to the deadman profile in the packed bed in the blast furnace, studies based on the cold model experiments, ${ }^{2-5)}$ slip-line analyses, ${ }^{3-7)}$ or in-furnace stress field analyses ${ }^{8)}$ with the dynamic burden descent condition taken into account have been made, and the theoretical characteristics of the stress field are now begun to be elucidated. However, there are few reports on the measurement of deadman profile and the analysis of actual furnace phenomena that cause the deadman profile to affect solid flow at the lower part of the furnace..$^{9-11)}$

Therefore, in the present study, the reduced stockline surface profile is measured from the reflection intensity of microwave $^{12)}$ struck from the furnace top after blow-off with stockline reduced, and countermeasures for the changes of raceway depth and furnace body profile during operation are reported with a hope to contribute to further improvement of the blast furnace operating technique.

\section{Method and Principle of Measuring Reduced Stock- line Surface Profile}

Figure 1 shows the furnace body profile of Kakogawa No. 1 blast furnace (tertiary) (inner volume $4550 \mathrm{~m}^{3}$, blown in on January 27, 1988) and how the microwave was struck. Measurement was carried out after blowing down is started in blow-off with stockline reduced, in which blast is continued even after charging is stopped when blowing down begins and the burden surface level is lowered. After blowing 


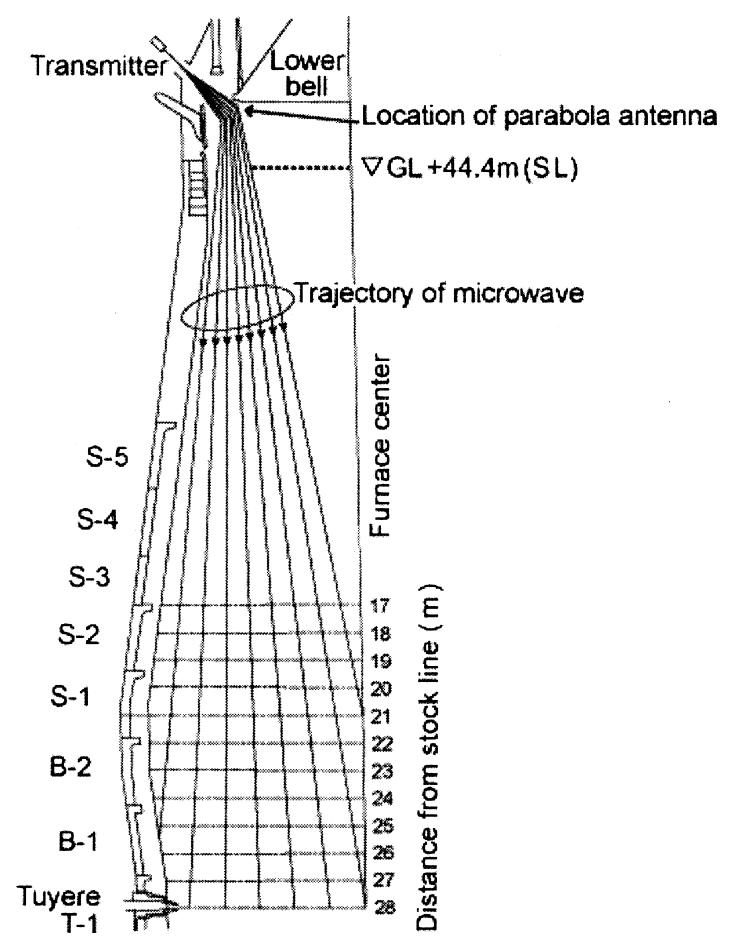

Fig. 1. Microwave technique to determine the deadman shape after schedule stopping with lowering stock level.

down is started, microwave is struck from the parabola antenna which is connected from the furnace top manhole to the waveguide tube. The struck microwave is combined with the received wave, and the burden surface profile can be measured from the frequency components of the beat wave generated. In measurement, by rotating the fixed axis of the parabola antenna of the manhole inlet, the total radius from the furnace wall to the central core is designated as the located subject in the bosh section. The assumed located distance of the reduced stockline surface profile is between $20 \mathrm{~m}$ and $30 \mathrm{~m}$.

Figure 2 shows the position locating results in the coke packed bed outside the furnace. It has been confirmed that the microwave measurement accuracy to the actual value is $0.32 \mathrm{~m}$ in the standard deviation. In the actual furnace, from May 9, 2000, measurement was carried out with the reduced stockline level varied after blowing down with stockline reduced was begun, and in such event, the accuracy of position location was confirmed by measurement (sounding device).

\section{Measurement Results of the Reduced Stockline Sur- face Profile and Discussion}

\subsection{Changes of Surface Profile Accompanied by Re- duced Stockline Level}

Figure 3 shows the measurement results of burden surface profile when the reduced stockline level is varied. Because the burden surface profile is subject to the burden descent to the raceway, in the peripheral section, dents are formed on the surface, and the lower the reduced stockline level, the greater is the dent tilting angle $\phi_{\mathrm{c}}$.

Hatano et al. $^{11)}$ assumed the existence of deadman coke at a tilting angle of $60^{\circ}$ in the lower part of furnace in investigating the blowing out operation with stockline reduced

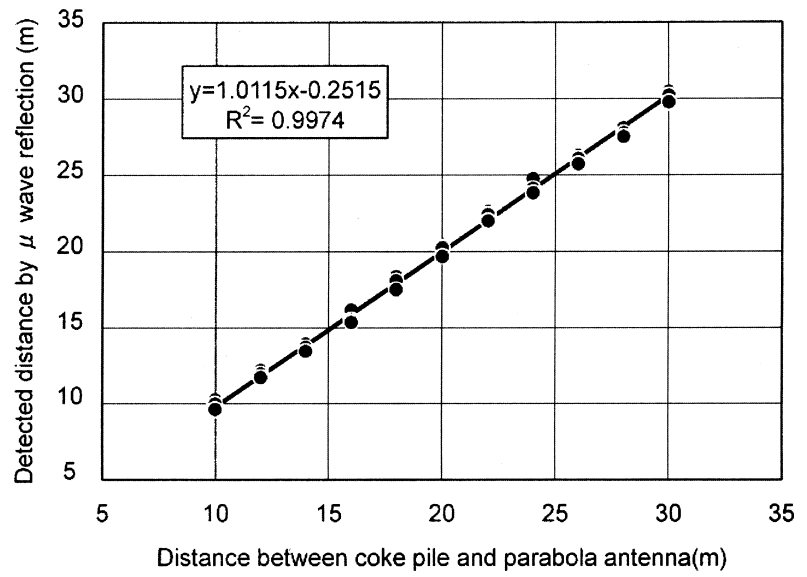

Fig. 2. Accuracy of micro wave reflection measurement for coke pile in yard test.

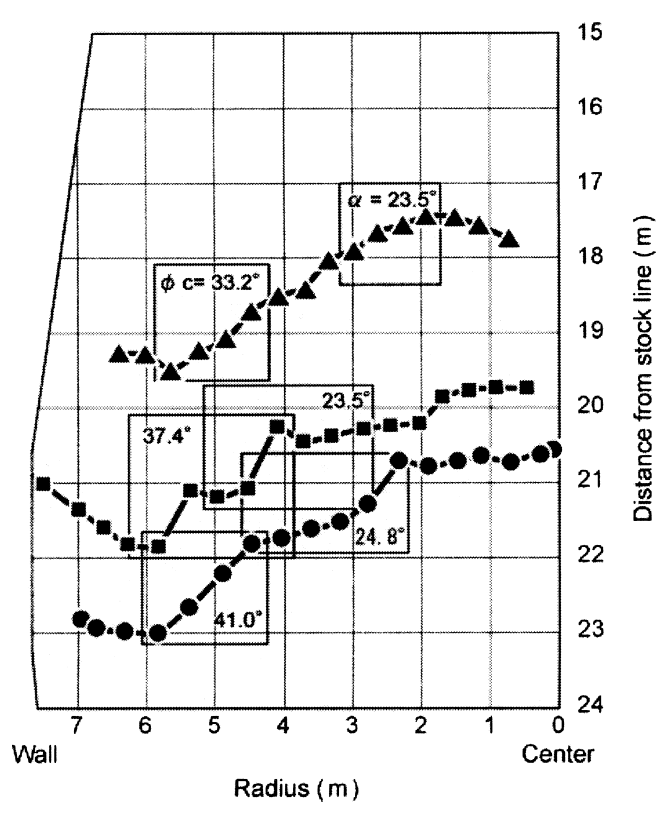

Fig. 3. Surface profiles measured after schedule stop.

by the blast-furnace mathematical formula model, and pointed out that in the last stage of stockline reduction, this deadman coke is exposed. In the present study, it has been confirmed that the tilting angle of the reduced stockline surface profile is formed by both tilting angle of the dent in the peripheral section and accumulation angle at the intermediate section. In addition, the accumulation angle $\alpha$ of the intermediate section indicates nearly constant value as against the tilting angle $\phi_{\mathrm{c}}$ of the dent in the peripheral section. Katayama et $a{ }^{8)}{ }^{8)}$ discriminates between the elastic condition and plastic condition in the stress analysis of the packed bed in the blast furnace, judges that the lower part of furnace including deadman is in the plastic condition, and assumes that the vicinity of the furnace wall at the lower part is in the passive condition.

Consequently, the fact that the accumulation angle $\alpha$ of the intermediate section indicates a nearly constant value suggests that because the reduced stockline level is below the lower shaft, the burden descent is subject to the bosh angle and the burden is compressed in the horizontal direction, and the reduced stockline surface is being pressed diagonally upwards. Therefore, assuming that the fine layer of 
the reduced stockline surface below the lower shaft was in the passive condition and the maximum main stress was applied in the surface direction, the internal friction angle $\phi_{\mathrm{i}}$ was found to be $42^{\circ}$ by $\alpha=(\pi / 4)-\left(\phi_{\mathrm{i}} / 2\right){ }^{13)}$

Katayama et $a l .^{8)}$ pointed out that the slip line analysis for the purpose of estimating the deadman profile is appropriate in the point that the lower shaft section is in the plastic condition but there remains a problem with respect to which should be assumed for the packed bed, in the active condition or in the passive condition. Consequently, the solid flow at the lower furnace section is assumed as follows and by checking the results with the actual furnace phenomena, the present assumption was verified.

\subsection{Estimation of Solid Flow Field at Lower Part of Furnace by Plastic Theory}

The powder flow field can be explained by both velocity discontinuous lines called slip line and velocity characteristic line which are deduced from the plastic theory. Takahashi et al. ${ }^{14)}$ confirmed that the particle flow in the two-dimensional moving bed can be characterized by both characteristic lines, in which deadman corresponds to the slip line and the boundary of the quasi-stagnant zone corresponds to the velocity characteristic line. In the present study, by applying the method of Takahashi et al., ${ }^{14)}$ the slip line profile was estimated.

Figure 4 shows the calculation results of the slip line that corresponds to the deadman surface and the velocity characteristic line that corresponds to the quasi-stagnant zone. By applying the method of Takahashi et al. ${ }^{14)}$ and fitting calculated data in straight line between wall and middle area, the deadman angle $\phi_{\mathrm{d}}$ that corresponds to the slip line was assumed to be $51.4^{\circ}$ and the quasi-stagnant zone angle $\phi_{\mathrm{v}}$ that corresponds to the velocity characteristic line was assumed to be $80.2^{\circ}$.

\section{Estimation of Solid Flow at the Lower Part of Fur- nace and Correspondence with the Phenomena in Actual Furnace}

\subsection{Estimation of Packed Structure at the Bosh and Correspondence with the Raceway Disintegration Cycle}

Because the bosh of the blast furnace is located right above the tuyere, it is subject to high thermal load and the erosion speed of brick is comparatively fast, and damage to the stave cooler attracts attention. ${ }^{15)}$ Furthermore, because the bosh is the portion where the coke supply path to the raceway becomes narrow and tight, it is the portion that governs the burden descent at the lower part of furnace, and it is assumed that it would affect damage to the stave cooler, too. In the present study, the powder pressure of the bosh was investigated from the viewpoint of the internal friction angle $\phi_{\mathrm{i}}$ and quasi-stagnant zone angle $\phi_{\mathrm{v}}$ obtained from the analysis discussed above.

Figure 5 shows the conceptional flow pattern and coordinate in bosh assumed as hopper.

Figure 6 shows the calculation results of the powder pressure distribution in the height direction of the bosh with the method of $\mathrm{Aoki}^{16)}$ of the powder pressure of the inverted conical hopper with symmetrical angle of $\phi_{\mathrm{v}}$ applied. In

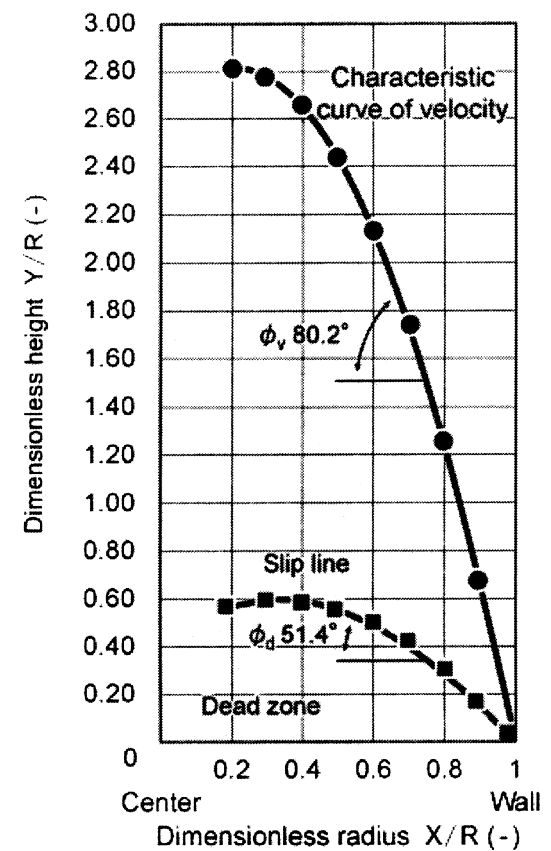

Fig. 4. Calculated slip line and characteristic curve of velocity in two dimensions.

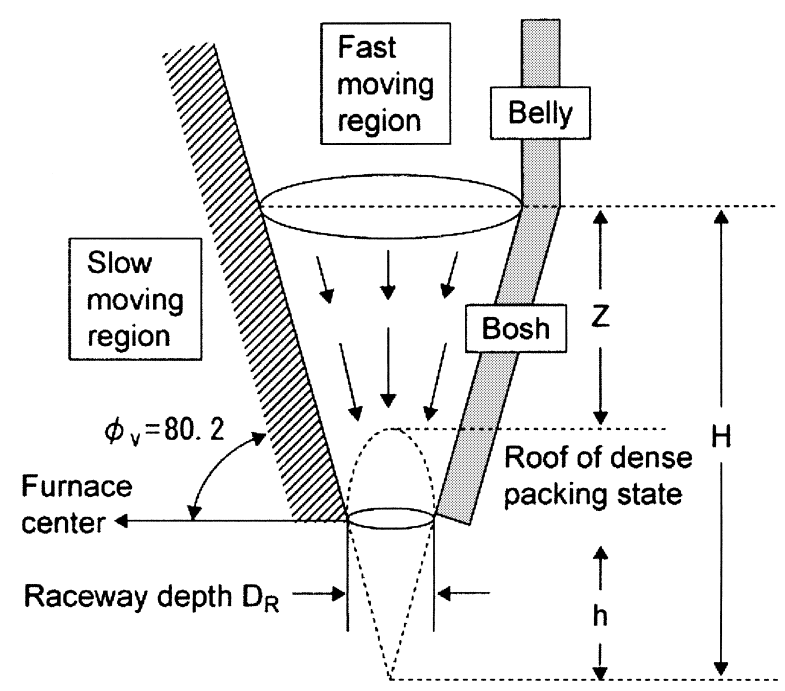

Fig. 5. Conceptional flow pattern and coordinate in bosh assumed as hopper.

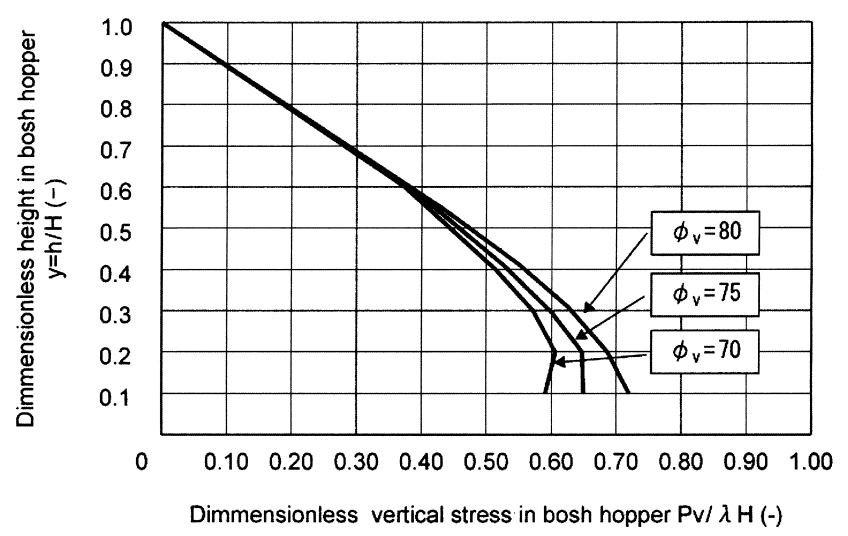

Fig. 6. Distribution of vertical pressure in bosh hopper.

this event, $\mathrm{Pv}$ denotes the powder pressure vertical component, $\lambda$ the bulk density, and $H$ the bosh height. In $y=h / H=0.2$, the powder pressure takes the maximum 


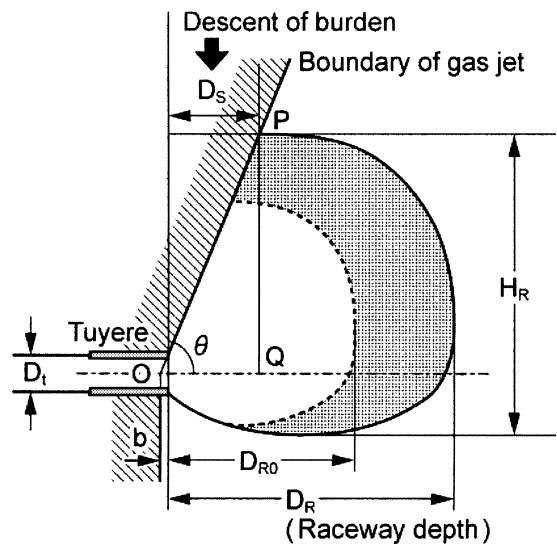

Fig. 7. Formation of raceway on collapsing cycle after Tamura et al. (1991).

value. This point indicates the specificity of the powder pressure of the inverted conical hopper, and the blocking phenomenon is likely to occur at the maximum value of this powder pressure. ${ }^{17)}$ Because it can be thought that this blocking phenomenon can be detected as a raceway disintegration cycle, verification was carried out by the raceway depth measurement results by the reflection intensity of microwave struck from the blast furnace tuyere as follows.

Figure 7 is a schematic representation by Tamura et al. ${ }^{18)}$ that indicates the dynamic process of the raceway which is formed by repeating the raceway extension and disintegration. By the raceway swirling movement and loads from above, the slip line OP is formed. Because the coke momentum in the raceway decreases due to coke combustion, the raceway extends to $D_{\mathrm{R}}$ in the figure by the excess gas momentum. On the other hand, since coke flows into the raceway, the gas momentum is imparted to the inflow coke, and the raceway contracts to $D_{\mathrm{R} 0}$ in the figure. It is assumed that the raceway repeats this extension and contraction in a short cycle to form a quasistationary raceway.

Because in the measurement of raceway depth by microwave reflection intensity, the peak detection position of microwave reflection intensity can be adopted as the raceway depth, in the short-cycle analysis, it is possible to detect the raceway depth at the time of contraction from the second peak detection position of the microwave reflection intensity. In addition, the transition time from the peak detection position to the second peak position was defined as the raceway disintegration cycle.

Figure 8 shows the effects of tuyere diameter on the measured raceway depth under the steady operation in measurement of raceway depth by microwave reflection intensity, ${ }^{19)}$ the second peak detection position and raceway disintegration cycle. The wider the tuyere diameter, the shallower is the second peak position and the shorter is the raceway disintegration cycle. This is assumed that since coke is distributed by differential pressure of each blast tuyere, the wider the tuyere diameter, the greater is the stock air volume and the greater is the flux of coke that enters the raceway, the raceway contracts in a short time, and at the same time, the raceway is likely to be reduced.

Tamura et $a l .{ }^{18)}$ report that the raceway disintegration cycle by coke luminance measurement under all coke operation of Kimitsu No. 3 blast furnace is between $5 \mathrm{~min}$ and
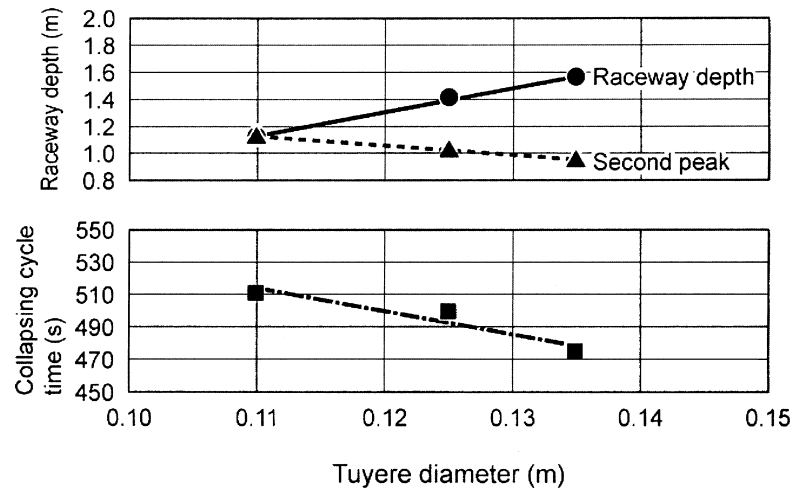

Fig. 8. Effect of tuyere diameter on raceway structure and collapsing cycle time.

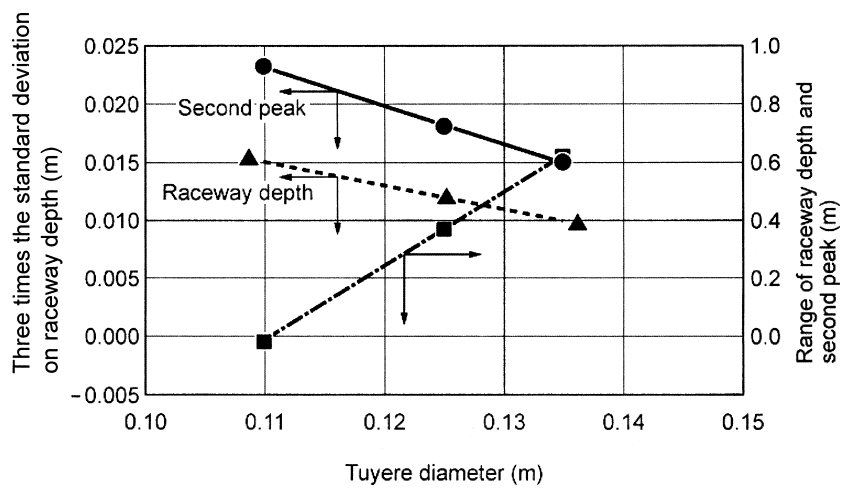

Fig. 9. Effect of tuyere diameter on raceway stability.

$6 \mathrm{~min}$, suggesting that the raceway disintegration cycle under PC injection is longer than that under all coke operation. It is assumed that the raceway stability can be evaluated by three factors, namely, first, the first peak fluctuation which is assumed to be able to represent stability of coke combustion in the raceway, second, the second peak fluctuation which is assumed to be able to represent the stability of coke inflow into the raceway, and the third, the distance between the first peak and the second peak as the degree of fluctuation of the raceway profile.

Figure 9 shows the relationship between range of raceway depth and second peak, three times the standard deviation on raceway depth, second peak and tuyere diameter. As the tuyere diameter increases, the measured raceway depth and fluctuation of the second peak detection position decreases, while the degree of the raceway depth fluctuation increases. Based on the foregoing, it is assumed that the raceway stability is greatly susceptible to the flux of coke that flows into the raceway, that is, the heat flow ratio at tuyere $^{20)}$ Consequently, it is assumed that under all coke operation with a high heat flow ratio at tuyere and under intensive PC injection with a low heat flow ratio at tuyere, factors that define the raceway stability would differ.

Hidaka et ll $^{21)}$ presents the following calculation formula of pulsation frequency of the hopper discharge flow rate, based on the relationship between the ultimate stress exerted on the slip line generated at the hopper section and the compacted powder bed height:

$$
f=\pi U \gamma_{\mathrm{d}}\left[\left(Z_{0}-Z_{4}\right) \tan \theta\right]^{2} /\left[W\left(\gamma_{\mathrm{s}}-\gamma_{\mathrm{d}}\right)\right]
$$

where, $Z_{0}$ : Hopper height (m) 
$Z_{4}$ : Distance from the hopper top surface to slip line generation position $(\mathrm{m})$

$\theta$ : Hopper opening half angle $\left(^{\circ}\right)$

$U:$ Mean drift velocity $(\mathrm{m} / \mathrm{s})$

$\gamma_{\mathrm{s}}$ : Bulk density of compacted powder bed $\left(\mathrm{kg} / \mathrm{m}^{3}\right)$

$\gamma_{\mathrm{d}}$ : Bulk density of powder bed in the fluidized state

$W$ : Compacted powder bed volume determined from the packed height when powder pressure becomes equal to the ultimate pressure $\left(\mathrm{m}^{3}\right)$

By the way, in the above formula, Hidaka et al. ${ }^{21)}$ determines volume $W$ of the compacted powder bed by assuming that the particle group which has a mean drift velocity $V$ in a hopper reduces the velocity at the compacted bed and comes into an instantaneous stop state, and finding the dynamic pressure from changes of the momentum, and correcting the mean vertical stress in the hopper by the Walters powder pressure calculation formula. ${ }^{22}$ )

In the present study, for the sake of simplicity, the volume of a truncated inverted conical hopper is found by using the raceway depth as a diameter, which is measured in an inverted cone that takes the maximum value of powder pressure at the inverted conical hopper found in Fig. 5 and whose dimensionless height is $y=\left(Z_{0}-Z_{4}\right) / Z_{0}=0.2$ or less, and the volume calculated is adopted for the volume $\mathrm{W}$ of the compacted powder bed as referring of change of bosh angle mentioned in Sec. 4.2. In addition, with respect to the bulk density $\gamma_{\mathrm{d}}$ of the powder bed when it comes into a fluidized state, the measured raceway was spherically approximated, and from the surface area, the specific velocity of the gas $U_{\mathrm{RW}}$ was calculated, and the bulk density $\gamma_{\mathrm{d}}$ of the fluidized-state powder bed was found from the bulk density $\gamma_{\mathrm{s}}$ of the compacted powder bed using the following equation by analogizing.

$$
Y_{\mathrm{d}}=Y_{\mathrm{s}}\left\{1-\left(U_{\mathrm{RW}} / U_{\mathrm{umf}}\right)^{2}\right\}
$$

where, $U_{\mathrm{RW}}$ : Outflow specific velocity of spouting gas from raceway surface $(\mathrm{m} / \mathrm{s})$

$U_{\text {umf: }}$ : Minimum fluidized velocity of coke $(\mathrm{m} / \mathrm{s})$

Figure 10 shows calculated values of fluidized powder bed bulk density for the measured raceway depth by microwave reflection intensity. As the raceway depth increases, the bulk density of fluidized powder bed increases. That is, because as the raceway depth increases, the coke supply path to the raceway expands, the coke that descends to the raceway in opposition to the ascending gas flow is likely to be compacted. Consequently, it is assumed that the deeper the raceway depth, the slower is the inflow velocity of coke into the raceway.

Figure 11 shows the relationship of the measured value of the raceway disintegration cycle by raceway depth measurement by reflection intensity of microwave to the calculated disintegration cycle found from Eq. (1) and Eq. (2) above. The measured raceway disintegration cycle by raceway depth measurement and calculated disintegration cycles nearly coincide.

Consequently, it is assumed appropriate to think that the inverted conical hopper formed by the quasi-stagnant zone angle $\phi_{\mathrm{v}}$ found in Fig. 4 is a coke supply path to the raceway.

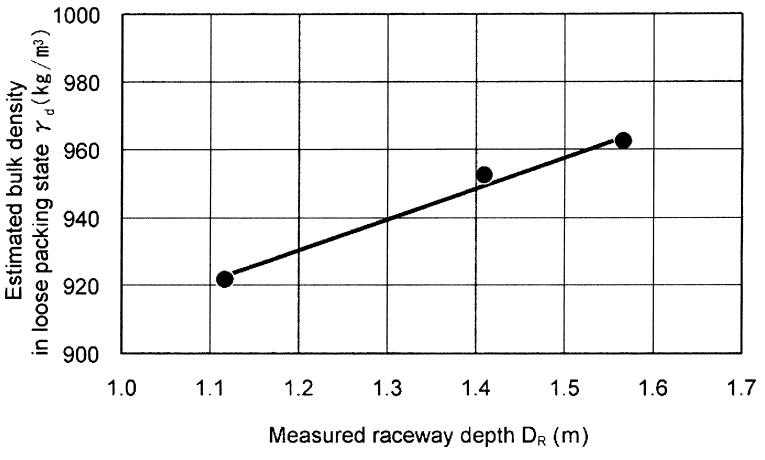

Fig. 10. Estimation of bulk density in loose packing state of bosh hopper.

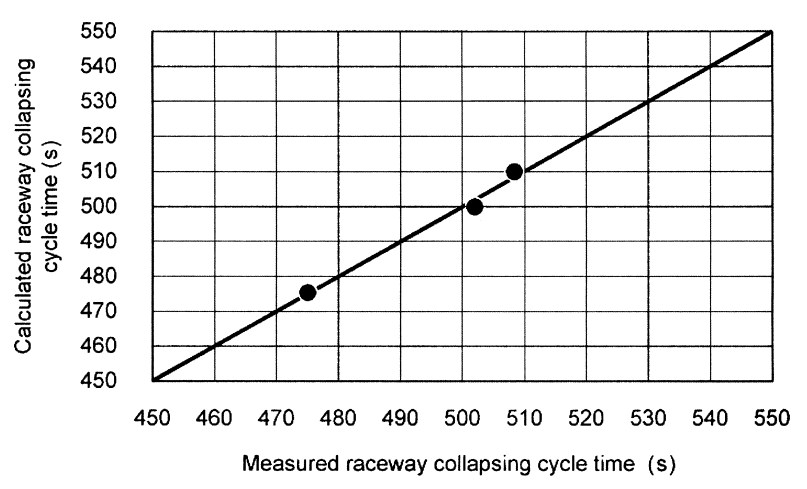

Fig. 11. Comparison of raceway collapsing cycle time between calculation and measurement.

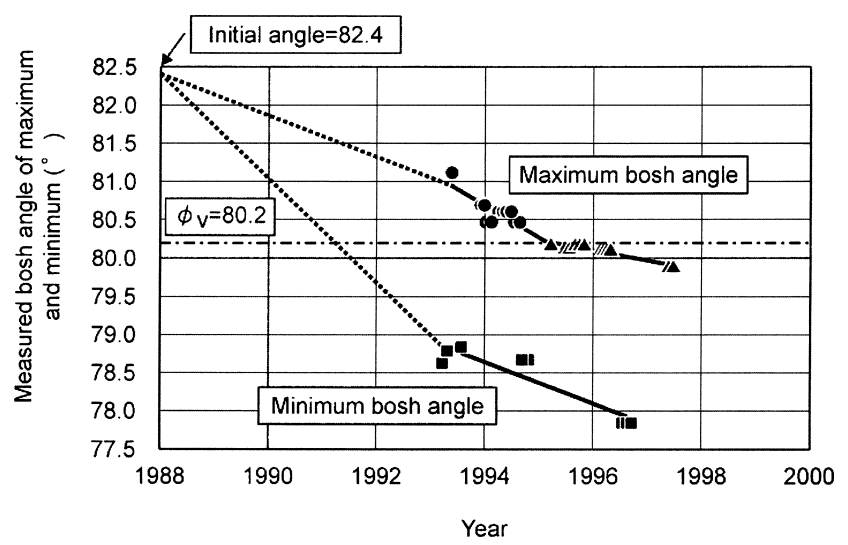

Fig. 12. Transition of bosh angle of Kakogawa No. 1 (3rd).

\subsection{Measures against Changes in Bosh Packed Struc- ture and Changes in Furnace Body Profile}

Because the bosh is the portion where the coke supply path to the raceway becomes narrow and tight, it is the portion that governs the burden descent at the lower part of furnace and abrasion with the furnace body by the above-mentioned pulsated descent is assumed to exert influence on damage to the furnace body profile.

Figure 12 shows changes with time of the maximum and minimum bosh angles measured in Kakogawa No. 1 blast furnace. The bosh angle was found from the residual thickness measured through scaffold measuring holes installed to the lower ends of the belly and the bosh, respectively. Because the bosh brick is worn and castings are partly worn, too, and formulation of the scaffold wall formed on the front surface of the bosh varies, the bosh angle changes 
with time with the range of maximum and minimum values maintained. In the present figure, when attention is focused on the maximum value of the bosh angle, it is found that the flexion point exists in the linearity for ageing. This flexion point is $80.2^{\circ}$ and it has been clarified that it coincides with the quasi-stagnant zone angle $\phi_{\mathrm{v}}$ that corresponds to the velocity characteristic line estimated from the reduced stockline surface measurement.

That is, if the bosh angle is not less than the quasi-stagnant zone angle $\phi_{\mathrm{v}}$, it is judged that the wear rate of the bosh is fast because the coke supply path is narrow.

Based on the foregoing, by verification of raceway disintegration cycle by measurement of raceway depth and changes with time of bosh angle, it is judged appropriate to assume that the powder bed on the reduced stockline surface below the lower shaft in Sec. 3.1 is in the passive state and the maximum main stress is in the surface direction.

\section{In-furnace Change in Whole Blast Furnace System Resulting in Blast Furnace Operation Limits}

Table 1 shows unsteady phenomena resulting in blast furnace operation limits from the dynamic viewpoint. ${ }^{23)}$ It is permeability that determines the blast furnace stability as well as the reducing agents rate from the result. The factors that bring about permeability fluctuation of blast furnace include fluctuation of burden distribution associated with fluctuation of particle size distribution of burdens, change in particle size distribution by in-furnace fine generation, fluctuation of cohesive zone profile as a result of these, and others, but all serve as permeability fluctuation via instability of gas flow. When permeability becomes poor, irregular burden descent and hanging are induced, and ill furnace condition in the whole blast furnace system is accompanied by hearth heat fluctuation results. Consequently, it is particularly important to identify in-furnace phenomena that induce instability of gas flow.

Figure 13 is a schematic representation by Poveromo ${ }^{24)}$ concerning the unsteady process of burden distribution and burden descent condition, or cohesive zone and raceway forms and the distribution condition. The burden distribution at the throat section for the purpose of controlling the cohesive zone profile via permeability resistance distribution at the shaft defines the radial and peripheral inflow

Table. 1. Unsteady phenomena forcing functional disorder on blast furnace performance of intensive coal injection.

\begin{tabular}{|c|c|c|c|c|}
\hline & \multirow{2}{*}{ Funcitons } & \multicolumn{3}{|c|}{ Functional disorder } \\
\hline & & Gas & Solid & Liquid \\
\hline \multirow{2}{*}{ Shaft } & $\begin{array}{l}\text { Gas distribution } \\
\text { by layer structure in height and radius }\end{array}$ & $\begin{array}{l}\text { Losing central } \\
\text { gas flow }\end{array}$ & $\square$ Hanging \& Slip & \\
\hline & $\begin{array}{l}\square \text { Burden distribution } \\
\text { by batch sequence }\end{array}$ & & $\begin{array}{l}\text { Unstable layer } \\
\text { structure }\end{array}$ & \\
\hline \multirow{2}{*}{$\begin{array}{l}\text { Bosh } \\
\text { \& Belly }\end{array}$} & $\begin{array}{l}\square \text { Gas distribution } \\
\text { from coke slits of cohesive zone }\end{array}$ & $\begin{array}{l}\square \text { Bypassing \& } \\
\text { Channeling }\end{array}$ & $\begin{array}{c}\square \text { Coke slit } \\
\text { chocking } \\
\text { Fluidizing } \\
\end{array}$ & \\
\hline & $\square$ Liquid distribution & & $\square$ Direct smelting & $\square$ Flooding \\
\hline \multirow{2}{*}{$\begin{array}{l}\text { Raceway } \\
\text { \& Hearth }\end{array}$} & $\begin{array}{l}\text { Gas distribution } \\
\text { by blast energy transformation }\end{array}$ & $\begin{array}{l}\text { Poor gas } \\
\text { penetration }\end{array}$ & $\begin{array}{l}\text { Backattack } \\
\text { on tuyere }\end{array}$ & Tuyere erosion \\
\hline & Drainage of liquid & & $\begin{array}{l}\square \text { Tap hole } \\
\text { chocking }\end{array}$ & U Umbalanced \\
\hline
\end{tabular}
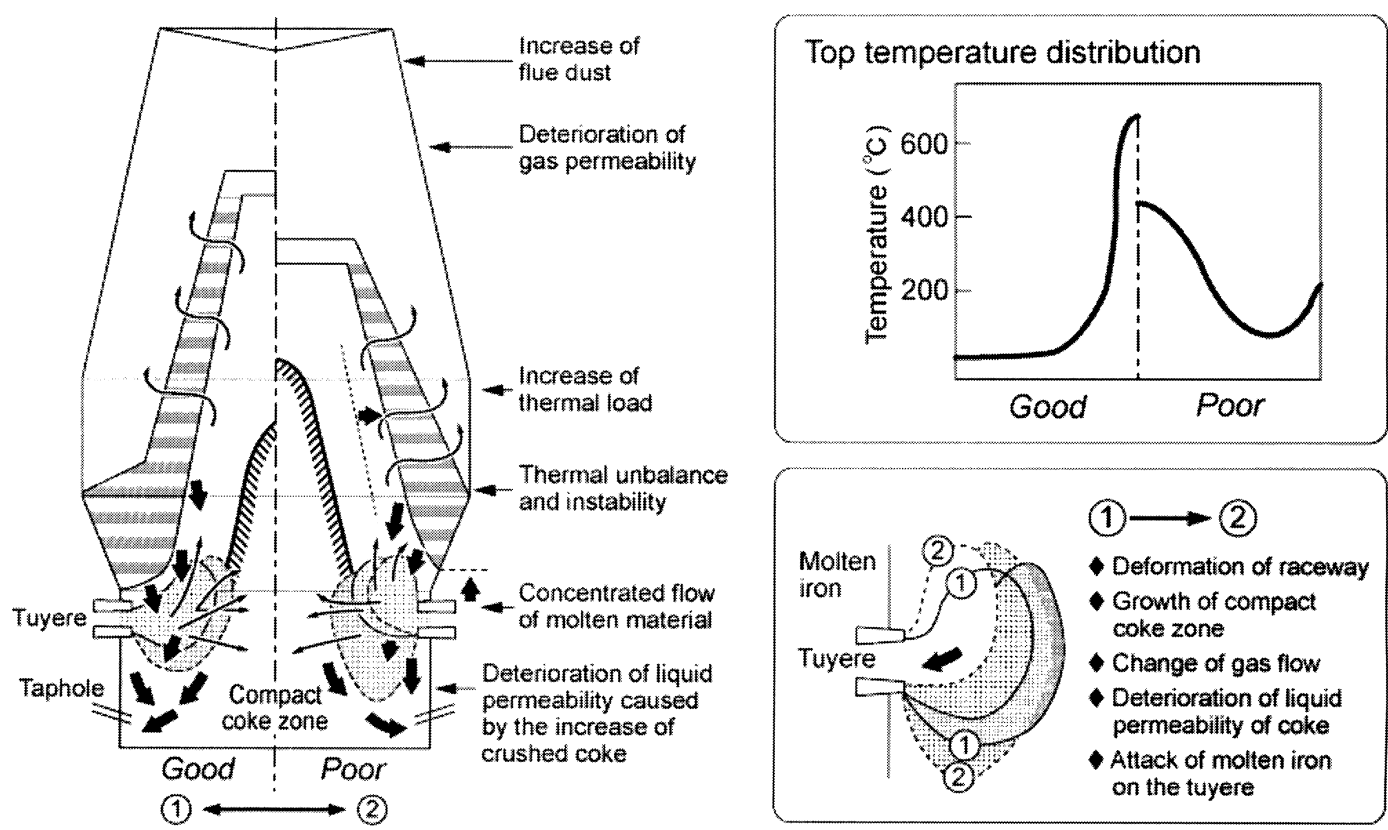

Fig. 13. Changes of gas flow, cohesive zone and raceways under unsteady state after Poveromo. 
forms of coke in the lower part of furnace, which is a singular packing structure, in the functions of the lower part of furnace. On the other hand, because coke gasification and combustion in the radial and peripheral directions govern the solid flow in the whole blast furnace system, it is particularly important to identify their in-furnace phenomena.

\section{Conclusion}

Great importance has been attached to the control of burden distribution and burden descent condition or control of deadman profile and solid flow in the lower part of furnace, etc. in the increased-size of blast furnace and high productivity operation. In the present study, the reduced stockline surface shape was measured from the reflection intensity of microwave incident from the furnace top after blow-off with stockline reduced, measures against changes in raceway depth and furnace body profile in operation were investigated, and the results of the work carried out allow us to draw the following conclusions.

(1) In the event that the reduced stockline level is below the lower part of shaft, burden descent is subject to the bosh angle, and the powder bed on the reduced stockline surface is in the passive state in which the burden is compressed in the horizontal direction, and by assuming that the maximum main stress is applied in the horizontal direction, the internal friction angle $\phi_{\mathrm{i}}$ is assumed to be $42^{\circ}$.

(2) From the slip line that corresponds to the deadman surface and the velocity characteristic line that corresponds to the quasi-stagnant zone, the deadman angle $\phi_{\mathrm{d}}$ that corresponds to the slip line is assumed to be $51.4^{\circ}$ and the quasi-stagnant angle $\phi_{\mathrm{v}}$ that corresponds to the velocity characteristic line is assumed to be $80.2^{\circ}$.

(3) Because the deeper the raceway depth, the more greatly the coke supply path to the raceway expands, the bulk density of coke that descends to the raceway in opposition to the ascending gas flow is likely to be compacted, and the inflow speed of coke into the raceway is assumed to be slow.

(4) The measured raceway disintegration cycle by measurement of raceway depth by reflection intensity of microwave coincides with the discharge disintegration cycle from an inverted conical hopper formed by the quasi-stagnant zone angle $\phi_{\mathrm{v}}$ obtained from the measurement of reduced stockline surface profile. Based on this, it has been verified that in the event that the reduced stockline level is below the lower part of shaft, the powder bed on the reduced stockline surface is in the passive state.

(5) Because the bosh is the portion where the coke supply path to the raceway becomes narrow and tight, it is the portion that governs the burden descent at the lower part of furnace and in the event that the bosh angle is not less than the quasi-stagnant zone angle $\phi_{\mathrm{v}}$, it has been verified that the wear rate of the bosh section is fast due to the narrow coke supply path.

Based on the foregoing, it has been clarified that coke flow into the lower part of blast furnace and flow into the raceway are greatly susceptible to the existence of deadman, which is the packed structure at the lower part of furnace, and as a result, they are closely related to the dynamic behavior of raceway.

The authors would like to mention that the present study is a successful product of both basic studies and actual furnace studies in the research conducted jointly by universities and private sector corporations of "Control of Blast Furnace Critical Phenomena for Minimum $\mathrm{CO}_{2}$ Generation" which was started in 2002.

\section{REFERENCES}

1) M. Tateoka: Tetsu-to-Hagané, 78 (1992), 957.

2) Y. Kuwano, M. Tate and J. Asamura: Tetsu-to-Hagané, 66 (1980), S633.

3) M. Shimizu, K. Yamaguchi, S. Inaba, and T. Narita: Tetsu-toHagané, 68 (1982), 936.

4) H. Takahashi, K. Kushima and T. Takeuchi: ISIJ Int., 29 (1989), 117.

5) K. Sato, S. Miyagawa, K. Takeda and H. Itaya: CAMP-ISIJ, 6 (1993), 887.

6) H. Nishio, W. Wenzel and H. W. Gudenau: Stahl Eisen, 97 (1977), 867.

7) M. Kuwabara, K. Isobe and K. Mio: Tetsu-to-Hagané, 74 (1988), 1734.

8) K. Katayama, S. Wakabayashi, T. Inada, K. Takatani and H. Yamaoka: Tetsu-to-Hagané, 83 (1997), 91.

9) T. Yonezawa and S. Ohta: Tetsu-to-Hagané, 43 (1957), 216.

10) T. Hayashizaki, S. Ohta, T. Kitagawa and S. Shimada: Tetsu-toHagané, 65 (1979), 2005.

11) M. Hatano, K. Kurita, H. Yamaoka and T. Yokoi: Tetsu-to-Hagané, 68 (1982), 2377.

12) C. Shibata and R. Horie: Tetsu-to-Hagané, 73 (1987), 1096.

13) S. Miwa: Powder Technology, Asakura Shoten, Tokyo, (1972).

14) H. Takahashi and H. Yanai: Kagaku Kogaku Ronbunshu, 38 (1974), 746.

15) A. Shigemi: Ironmaking Handbook, Chijin Shokan Co., Ltd., Tokyo, (1979).

16) R. Aoki: Hopper and Feeder of Powders, The Nikkan Kogyo Shimbun, Ltd., Tokyo, (1963).

17) J. Sakashita: Powder Trouble Engineering, Kogyo Chosakai Publishing Inc., Tokyo, (1985).

18) K. Tamura, M. Ichida, H. Ueno, and K. Yamaguchi: Mcmaster Symp., No. 19, (1991), 303.

19) Y. Matsui, Y, Yamaguchi, M. Sawayama, S. Kitano, N. Nagai and T. Imai: ISIJ Int., 45 (2005), 1432.

20) P. C. Chaubal: Mcmaster Symp., No. 19, (1991), 25.

21) S. Hidaka, J. Kano and A. Shimosaka: Chem. Eng. Sci. J., 20 (1994), 397.

22) J. K. Walters: Chem. Eng. Sci. J., 28 (1973), 13.

23) Y. Matsui, J. Yamagata, K. Nozawa, K. Shibata, T. Matsuo and R. Ono: CAMP-ISIJ, 16 (2003), 764.

24) J. J. Poveromo: Iron Steelmaker, (1995), May, 64. 